The published version of this paper should be considered authoritative, and any citations or page references should be taken from it.

Zhang*, T., Van Heuven, W.J.B., \& Conklin, K. (2011). Fast automatic translation and morphological decomposition in Chinese-English bilinguals. Psychological Science, 22(10), 1237-1242. [DOI: 10.1177/ 0956797611421492]

\title{
Fast Automatic Translation and Morphological Decomposition in Chinese- English Bilinguals
}

\author{
Taoli Zhang ${ }^{1}$,Walter J. B. van Heuven ${ }^{1}$, and Kathy Conklin ${ }^{2}$ \\ ${ }^{1}$ School of Psychology and ${ }^{2}$ School of English Studies, University of Nottingham
}

\begin{abstract}
In this study, we investigated automatic translation from English to Chinese and subsequent morphological decomposition of translated Chinese compounds. In two lexical decision tasks, Chinese-English bilinguals responded to English target words that were preceded by masked unrelated primes presented for $59 \mathrm{~ms}$. Unbeknownst to participants, the Chinese translations of the words in each critical pair consisted of a fully opaque compound word (i.e., a compound with two constituent morphemes that were semantically unrelated to the compound) and a monomorphemic word that was either the first or the second morpheme of the compound. The data revealed that bilinguals responded faster to English word pairs whose Chinese translations repeated the first morpheme than to English word pairs whose Chinese translations did not repeat the first morpheme, but no effect of hidden second-morpheme repetition was found. This effect of hidden first-morpheme repetition suggests that participants translated English words to Chinese and decomposed the translated compounds into their constituent morphemes. Because the primes were presented for only 59 ms, translation and morphological decomposition must be fast and automatic.
\end{abstract}

\section{Keywords}

bilingualism, word recognition, priming

A fundamental question about bilinguals' ability to translate words between two languages is whether this translation process operates not only under the bilinguals' conscious control (e.g., in an explicit translation task) but also automatically and unconsciously when they read words in one of their languages. The existing evidence for automatic translation in bilinguals comes from studies that have used cross-language priming. These studies have shown that the recognition of targets in one language is facilitated by translation-equivalent primes in the other language (for a review, see Dunabeitia, Perea, \& Carreiras, 2010).

However, cross-language priming involves a mix of stimuli from two languages, which encourages a bilingual activation pattern (Thierry \& Wu, 2007). To avoid this potential confound, Thierry and $\mathrm{Wu}$ presented Chinese-English bilinguals (native Chinese speakers who speak English as a second language) with English word pairs in a semantic-relatedness task. In each pair, the first and the second word were either related in meaning (e.g., "post" and "mail") or not (e.g., "train" and "ham"). Unbeknownst to participants, the Chinese translations for half of the English word pairs contained repeated morphemes (e.g., the Chinese translations for post, 邮政, and mail, 邮件, both contain the morpheme 邮). Because the English word pairs were orthographically unrelated, any effect of the covert repetition of Chinese morpheme could have originated only from the activation of the bilinguals' native language. Participants exhibited a reduced N400 amplitude (an eventrelated potential component that is considered a measure of semantic activation processes) for English word pairs whose Chinese translations shared a morpheme relative to English word pairs whose Chinese translations did not share a morpheme. The authors concluded that bilinguals' knowledge of their first language is activated in the context of their second language.

It is important to note that Thierry and Wu (2007) might have presented the first words in the pairs for a sufficiently long amount of time (e.g., $500 \mathrm{~ms}$ ) to allow participants to translate them before the second words appeared. To avoid such strategic processing among participants in the experiments reported here, we asked participants to make lexical decisions on target words that were preceded by masked prime 
words exposed for only $59 \mathrm{~ms}$. When the critical word pairs were translated into Chinese, the Chinese translations consisted of a fully opaque compound word and a monomorphemic word that was either the compound's first or second morpheme. For example, one of the English word pairs was east-thing; the Chinese translation of east, 东, is the first morpheme of the compound 东西, meaning "thing." Another of the English word pairs was west-thing; the Chinese word for west, 西, is the second morpheme of the compound 东西. This hidden repetition of morphemes was possible because each opaque Chinese compound whose English translation was used consists of two morphemes that can stand alone as monomorphemic words whose meanings are unrelated to the meaning of the compound. Effects of hidden morpheme repetition could occur only if the participants translated the English words into Chinese and then decomposed the Chinese compounds into their morphological constituents.

Priming studies have demonstrated that in several languages, morphological segmentation occurs independently of the semantic relationship between compounds and their constituents (English: Libben, Gibson, Yoon, \& Sandra, 2003; French and Bulgarian: Jarema, Busson, Nikolova, Tsapkini, \& Libben, 1999; Chinese: Peng, Li, \& Liu, 1994; Wang \& Peng, 2000); in these studies, prime durations were between $100 \mathrm{~ms}$ and $200 \mathrm{~ms}$. In more recent studies, researchers have examined earlier stages of morphological decomposition by presenting primes for durations shorter than $60 \mathrm{~ms}$ (see Rastle \& Davis, 2008, for a review) and have reported that a multisyllabic word is decomposed into its constituent parts even when the meaning of the word cannot be derived from any of its constituents. For example, the word corner is decomposed into corn and $-e r$, despite the fact that $-e r$ is a pseudosuffix and the meaning of corner cannot be derived from corn (e.g., Gold \& Rastle, 2007; Lavric, Clapp, \& Rastle, 2007; MarslenWilson, Bozie, \& Randall, 2008; McCormick, Rastle, \& Davis, 2008; Rastle, Davis, \& New, 2004). These studies examined the processing of derivational affixes in IndoEuropean languages, whereas we investigated the processing of Chinese compounds whose constituent morphemes can stand alone (as, in English, the two constituent morphemes of deadline can stand alone). We employed hidden morphemerepetition priming, with the morphemes being repeated only in the Chinese translations of the English word pairs. In each English word pair, the target and prime were orthographically, phonologically, and semantically unrelated.

In sum, we investigated automatic translation and morphological decomposition in combination in an attempt to answer two key questions. First, do Chinese-English bilinguals automatically translate English to Chinese? Second, if they activate opaque Chinese compounds through such automatic translation, do they decompose the compounds into their constituent morphemes? In Experiment 1, participants completed a lexical decision task in which on each critical trial, the English translation of a fully opaque Chinese compound was used as the target, and that target was preceded by a masked, briefly presented English prime whose Chinese translation corresponded to the first or second morpheme of the Chinese compound. The target remained on-screen until participants responded, so they potentially had enough time to translate the target and decompose it. To limit participants' time for translation and morphological decomposition, we reversed the order of presentation of the primes and targets in Experiment 2. In this experiment, participants completed a lexical decision task in which English targets corresponding to single morphemes in Chinese were preceded by masked English primes, presented for $59 \mathrm{~ms}$, that corresponded to opaque Chinese compounds that included those morphemes. Thus, participants had only a short time to translate and morphologically decompose the Chinese compounds that corresponded to the primes. In addition to testing Chinese-English bilinguals, we included monolingual English speakers as participants in both experiments to control for any potential priming effects due to the properties of the English primes and targets.

\section{Method Participants}

Participants were 64 Chinese-English bilinguals (32 in Experiment 1 and 32 in Experiment 2) and 64 English monolinguals (32 in Experiment 1 and 32 in Experiment 2). All participants were from the University of Nottingham and were monetarily compensated for taking part in the study. At the time of the experiments, the bilingual participants had studied English for an average of 12 years and had been living in the United Kingdom for an average of 14 months. Using Likert scales from 1 (poor) to 10 (native), the bilingual participants rated their proficiency in Chinese $(M=9.8)$ as significantly higher than their proficiency in English $(M=6.7), F(1,63)=291.1, p<.001$.

\section{Materials}

Forty fully opaque, two-character Chinese compounds were selected. In Experiment 1, the English translations of these compounds were used as target words. Each was preceded by one of four types of primes: (a) the English translation of the first morpheme of the Chinese compound (hidden first-morpheme repetition), (b) an English control word matched in length and lexical frequency with the hidden-first-morpheme-repetition prime, (c) the English translation of the second morpheme of the Chinese compound (hidden second-morpheme repetition), or (d) an English control word matched in length and lexical frequency with the hidden-second-morpheme-repetition prime. In Experiment 2, the targets from Experiment 1 were used as primes, and the hidden-first-morpheme-repetition and hiddensecond-morpheme-repetition primes from Experiment 1 were used as targets. Thus, the critical primes in Experiment 2 were English translations of the 40 Chinese opaque compounds. A new set of 40 English words matched in length and lexical frequency with the critical primes were used as control primes in 
Experiment 2. Table 1 shows the lexical properties of the stimuli for both experiments. English pseudowords (40 in Experiment 1 and 80 in Experiment 2) were created for the purpose of the lexical decision tasks. All pseudoword targets were primed with legitimate English words. Counterbalanced lists of word pairs (four in Experiment 1 and two in Experiment 2) were constructed so that each target appeared once in each list, but each time in a different priming condition. Participants were randomly assigned to one of the lists.

\section{Procedure}

Participants were tested individually in a dimly lit room. On each trial, participants first viewed a forward mask ${ }^{1}$ (\$@\#\$£@£\%), presented for 500 ms. The mask was immediately followed by a lowercase prime word (in 14-point Courier New font). The prime was presented for $59 \mathrm{~ms}$ and followed by a backward mask (\%\$\%£@£\$\#), presented for $23 \mathrm{~ms}$. This second mask was followed by the target, an uppercase letter string (in 16-point Courier New font). Participants were not informed about the presence of the primes. Participants were instructed to indicate as quickly and as accurately as possible whether or not each uppercase letter string was an English word. The targets remained on-screen until participants made a response. Responses were made using a button box, and reaction times (RTs) were measured from target onset until response. Targets were presented in a different random order for each participant. DMDX Display Software (Forster \& Forster, 2003) was used to control stimulus presentation and record RTs.

\section{Results}

For each experiment, data for Chinese-English bilinguals and English monolinguals were analyzed separately. RTs less than $300 \mathrm{~ms}$ or more than $2,500 \mathrm{~ms}$ were discarded as outliers
(Experiment 1: $0.6 \%$ of responses for bilinguals and $0.4 \%$ of responses for monolinguals; Experiment 2: 0.8\% of responses for bilinguals and $0.2 \%$ of responses for monolinguals). Incorrect responses (Experiment 1: 10.4\% of responses for bilinguals and $3.9 \%$ of responses for monolinguals; Experiment 2: $10.8 \%$ of responses for bilinguals and $6.2 \%$ of responses for monolinguals) were also discarded. Mean RTs for correct responses and mean error rates were calculated across individuals (see Tables 2 and 3). Position (first vs. second morpheme of the Chinese compound) and hidden morpheme repetition (repetition vs. no repetition) were manipulated within subjects. Word list was included as a dummy betweensubjects factor (Pollatsek \& Well, 1995).

\section{Experiment 1}

Analyses of RTs for Chinese-English bilinguals in Experiment 1 revealed a reliable effect of hidden morpheme repetition, $F_{1}(1$, $28)=6.09, p<.05, \eta^{2}=.18$, and $F_{2}(1,39)=3.84, p<.05, \eta^{2}=$ .10. We found no effect of position, $F_{\mathrm{s}}<1$, but found an interaction between position and hidden morpheme repetition, $F_{1}(1,28)=15.56, p<.001, \eta^{2}=.36$, and $F_{2}(1,38)=4.43, p<$ $.05, \eta^{2}=.10$. The interaction reflected a significant priming effect for hidden first-morpheme repetition $(75 \mathrm{~ms}), F_{1}(1,28)=$ $21.70, p<.001, \eta^{2}=.44$, and $F_{2}(1,39)=6.88, p<.05, \eta^{2}=$ .15 , and the lack of a priming effect for hidden secondmorpheme repetition $(12 \mathrm{~ms}), F \mathrm{~s}<1$. No significant effects were found in the error analyses (all $p \mathrm{~s}>.20$ ).

No significant effects were found in the analyses of English monolinguals' RTs or error rates (all $F \mathrm{~s}<1$ ).

\section{Experiment 2}

Analyses of the RTs for Chinese-English bilinguals in Experiment 2 revealed a significant effect of hidden morpheme

Table 1. Mean Lexical Frequency and Word Length of the English Prime and Target Words Used in Experiments 1 and 2

\begin{tabular}{|c|c|c|c|c|c|}
\hline \multirow[b]{2}{*}{$\begin{array}{l}\text { Experiment and } \\
\text { characteristic }\end{array}$} & \multicolumn{2}{|c|}{ Hidden first-morpheme repetition } & \multicolumn{2}{|c|}{ Hidden second-morpheme repetition } & \multirow[b]{2}{*}{ Targets } \\
\hline & $\begin{array}{l}\text { Primes with hidden } \\
\text { repetition }\end{array}$ & $\begin{array}{l}\text { Matched primes with } \\
\text { no repetition }\end{array}$ & $\begin{array}{l}\text { Primes with hidden } \\
\text { repetition }\end{array}$ & $\begin{array}{l}\text { Matched primes with } \\
\text { no repetition }\end{array}$ & \\
\hline \multicolumn{6}{|l|}{ Experiment 1} \\
\hline Lexical frequency & 422 & 423 & 401 & 419 & 166 \\
\hline Word length & 5.0 & 5.0 & 4.9 & 4.9 & 6.3 \\
\hline \multicolumn{6}{|l|}{ Experiment 2} \\
\hline Lexical frequency & 166 & 171 & 166 & 171 & $422 / 401$ \\
\hline Word length & 6.3 & 6.3 & 6.3 & 6.3 & $5.0 / 4.9$ \\
\hline
\end{tabular}

Note: In Experiment 1, targets were English translations of Chinese compounds (e.g., thing, 东西), and primes with hidden Chinese-morpheme repetition were the English translations of the first morpheme (e.g., east, 东 ) or second morpheme (e.g., west, 西) of the compound words. In Experiment 2, targets were the English translations of the first morpheme (e.g., east, 东) or second morpheme (e.g., west, 西) of Chinese compound words, and primes with hidden Chinese-morpheme repetition were the English translations of the Chinese compounds (e.g., thing, 东西). In the Targets column, the two numbers in each cell for Experiment 2 refer to primes with hidden first-morpheme repetition and hidden secondmorpheme repetition, respectively. Control primes did not contain repeated morphemes and were matched with hidden-repetition primes on lexical frequency and word length. Frequency (per million words) was taken from the CELEX lexical database (Baayen, Piepenbrock, \& van Rijn, 1993). Word length refers to the number of letters in the words. 
Table 2. Mean Reaction Times (RTs) and Error Rates for Chinese-English Bilinguals and English Monolinguals in Experiment 1

\begin{tabular}{|c|c|c|c|c|}
\hline \multirow[b]{2}{*}{ Repetition condition } & \multicolumn{2}{|c|}{ Chinese-English bilinguals } & \multicolumn{2}{|c|}{ English monolinguals } \\
\hline & $\mathrm{RT}$ (ms) & Errors (\%) & $\mathrm{RT}(\mathrm{ms})$ & Errors $(\%)$ \\
\hline \multicolumn{5}{|l|}{ Hidden first-morpheme repetition } \\
\hline Primes with hidden repetition & $930(35)$ & 6.6 & $572(16)$ & 2.5 \\
\hline Matched primes with no repetition & $1,005(39)$ & 9.7 & $575(15)$ & 2.2 \\
\hline Priming effect & $75^{\star *}$ & 3.1 & 3 & -0.3 \\
\hline \multicolumn{5}{|l|}{ Hidden second-morpheme repetition } \\
\hline Primes with hidden repetition & $958(32)$ & 8.4 & $559(12)$ & 2.5 \\
\hline Matched primes with no repetition & $946(32)$ & 8.4 & $560(14)$ & 3.8 \\
\hline Priming effect & -12 & 0.0 & 1 & 1.3 \\
\hline
\end{tabular}

Note: Standard errors are given in parentheses.

${ }^{* *} p<.001$.

repetition, $F_{1}(1,30)=3.12, p<.05, \eta^{2}=.09$, and $F_{2}(1,39)=$ 4.01, $p<.05, \eta^{2}=.09$, and a by-subjects effect of position, $F_{1}(1,30)=9.52, p<.05, \eta^{2}=.24\left(F_{2}<1\right)$. Analyses also revealed an interaction between hidden morpheme repetition and position, $F_{1}(1,30)=7.27, p<.05, \eta^{2}=.20$, and $F_{2}(1$, $39)=3.32, p<.05, \eta^{2}=.08$. As in Experiment 1 , the interaction reflected the fact that there was a facilitation effect (48-ms difference) for hidden first-morpheme repetition, $F_{1}(1,30)=11.30$, $p<.05, \eta^{2}=.27$, and $F_{2}(1,39)=6.86, p<.05, \eta^{2}=.15$, and no facilitation effect (5-ms difference) for hidden secondmorpheme repetition, $F_{\mathrm{S}}<1$. Error analyses showed a bysubjects effect of position, $F_{1}(1,30)=7.28, p<.05, \eta^{2}=.20$, but no by-items effect of position, $F_{2}(1,39)=2.45, p=.13$. There were no other significant effects in error analyses, $F_{\mathrm{S}}<1$.

No significant effects were found in analyses of the RTs or error rates of English monolinguals (all $F \mathrm{~s}<1$ ).

\section{Discussion}

In two lexical decision tasks using English words as stimuli, Chinese-English bilinguals and English monolinguals responded to target words that were preceded by briefly presented, unrelated masked prime words. On critical trials, the English primes and targets, once translated into Chinese, were morphologically related. Experiment 1 showed that ChineseEnglish bilinguals' recognition of English words that translated into compound words in Chinese was facilitated by English primes corresponding to the first morphemes in these compounds, but not by English primes corresponding to the compounds' second morphemes. The results from the ChineseEnglish bilinguals in Experiment 2 extended those obtained in Experiment 1: English primes that translated into compound words in Chinese facilitated the recognition of English targets that translated to the first morphemes of the translated primes, but not targets that translated to the second morphemes of the translated primes. These results constitute evidence for fast automatic translation and morphological decomposition in Chinese-English bilinguals. ${ }^{2}$ The responses of English monolinguals were not affected by the hidden morpheme repetition in either experiment, a result indicating that the observed effects were unique to the Chinese-English bilinguals and were not due to characteristics of the English primes and targets.

Our finding that bilinguals automatically activate firstlanguage translation equivalents in a second-language lexical

Table 3. Mean Reaction Times (RTs) and Error Rates for Chinese-English Bilinguals and English Monolinguals in Experiment 2

\begin{tabular}{|c|c|c|c|c|}
\hline \multirow[b]{2}{*}{ Repetition condition } & \multicolumn{2}{|c|}{ Chinese-English bilinguals } & \multicolumn{2}{|c|}{ English monolinguals } \\
\hline & $\mathrm{RT}(\mathrm{ms})$ & Errors (\%) & $\mathrm{RT}(\mathrm{ms})$ & Errors (\%) \\
\hline \multicolumn{5}{|l|}{ Hidden first-morpheme repetition } \\
\hline Primes with hidden repetition & $948(24)$ & 4.5 & $536(10)$ & 3.3 \\
\hline Matched primes with no repetition & $996(24)$ & 5.3 & $533(10)$ & 4.2 \\
\hline Priming effect & $48^{*}$ & 0.8 & -3 & 0.9 \\
\hline \multicolumn{5}{|l|}{ Hidden second-morpheme repetition } \\
\hline Primes with hidden repetition & $1,015(30)$ & 8.1 & $536(11)$ & 4.5 \\
\hline Matched primes with no repetition & $1,010(28)$ & 6.1 & $532(11)$ & 3.8 \\
\hline Priming effect & -5 & 2.0 & -4 & -0.7 \\
\hline
\end{tabular}

Note: Standard errors are given in parentheses. ${ }^{*} p<.05$. 
decision task is consistent with the findings of previous comprehension studies using semantic-relatedness judgment tasks (e.g., Morford, Wilkinson, Villwock, Pinar, \& Kroll, 2011; Thierry \& Wu, 2004). Thierry and $\mathrm{Wu}$ (2004) found that hidden repetition of Chinese morphemes resulted in slowed responses to English word pairs (i.e., negative priming) in Chinese-English bilinguals. In contrast, hidden morpheme repetition in our experiments resulted in positive priming effects. One possible explanation for this difference is that semantic-relatedness judgments are made on the basis of the meaning of words; in this context, the hidden repetition of Chinese morphemes can be counterproductive and result in interference. However, lexical decisions can be made on the basis of orthographic information (Grainger \& Jacobs, 1996); thus, in lexical decision tasks, the hidden repetition of morphemes can be helpful and speed up target recognition.

The effects of hidden first-morpheme repetition suggest that the Chinese opaque compounds were decomposed into their component morphemes. Previous monolingual studies on the decomposition of Chinese compounds using morphemerepetition priming paradigms have always presented stimuli in Chinese. Using a prime duration of $56 \mathrm{~ms}$, Peng, Liu, and Wang (1999) found no effects of morpheme-repetition priming for opaque-compound pairs (e.g., target: 快活, "happy"; prime: 快速, "rapidly"; repeated morpheme: 快). One potential explanation for these different patterns of results is that in our experiments, the Chinese translations of either primes or targets were one-character words, whereas in the study by Peng et al., both primes and targets were two-character Chinese words. It is possible that (hidden) repetition priming using single-character words is more salient than (overt) repetition priming using two-character words.

There are mixed findings in the literature concerning the relative contribution of each constituent in the processing of compounds. Some studies have demonstrated a firstmorpheme advantage (e.g., Kuperman, Schreuder, Bertram, \& Baayen, 2009; Peng et al., 1994), and others have demonstrated a second-morpheme advantage (e.g., Juhasz, Starr, Inhoff, \& Placke, 2003). We observed effects of firstmorpheme repetition only; this finding suggests that the first morpheme is activated faster than the second in compound recognition. It is important to note that compounds in our study were activated via translation from English. Thus, the priming effects in our experiments provide unique evidence for the morphological decomposition of automatically translated Chinese compounds in the bilingual brain.

In sum, our data provide strong evidence for automatic translation from English to Chinese in Chinese-English bilinguals and for the morphological segmentation of translated compounds. Future research is needed to determine whether or not these findings can be generalized to bilingual speakers of different languages. Our data show that automatic translation and morphological decomposition occur very rapidly in Chinese-English bilinguals, indicating that these two processes are highly automatic.

\section{Declaration of Conflicting Interests}

The authors declared that they had no conflicts of interest with respect to their authorship or the publication of this article.

\section{Notes}

1. In Experiment 2, the mask failed to completely cover five words (three 9-letter words and two 10-letter words). However, the patterns of results remained the same when these items were excluded from the analyses.

2. Because second-language word learning often occurs through translation, when Chinese-English bilinguals learn English words whose Chinese translations are compounds, such English words may have connections to English words whose Chinese translations are the constituents of those compounds. It is possible that the effects of hidden Chinese-morpheme repetition in Chinese-English bilinguals' English comprehension reflect the transfer of these connections, which could result in priming effects in both directions (i.e., from the compounds to their constituents and vice versa). However, we found that hidden repetition of a constituent morpheme produced a priming effect only when the morpheme was the first morpheme of the Chinese compound. Therefore, the most parsimonious explanation for the priming effects in our experiments is that they were the result of automatic translation.

\section{References}

Baayen, R. H., Piepenbrock, R., \& van Rijn, H. (1993). The CELEX lexical database [CD-ROM]. Philadelphia: University of Pennsylvania, Linguistic Data Consortium.

Dunabeitia, J. A., Perea, M., \& Carreiras, M. (2010). Masked translation priming effects with highly proficient simultaneous bilinguals. Experimental Psychology, 57, 98-107.

Forster, K. I., \& Forster, J. C. (2003). DMDX: A Windows display program with millisecond accuracy. Behavior Research Methods, Instruments, \& Computers, 35, 116-124.

Gold, B., \& Rastle, K. (2007). Neural correlates of morphological decomposition during visual word recognition. Journal of Cognitive Neuroscience, 19, 1983-1993.

Grainger, J., \& Jacobs, A.M. (1996). Orthographic processing in visual word recognition: A multiple read-out model. Psychological Review, 103, 518-565.

Jarema, G., Busson, C., Nikolova, R., Tsapkini, K., \& Libben, G. (1999). Processing compounds: A cross-linguistic study. Brain and Language, 68, 362-369.

Juhasz, B. J., Starr, M. S., Inhoff, A. W., \& Placke, L. (2003). The effects of morphology on the processing of compound words: Evidence from naming, lexical decisions and eye fixations. British Journal of Psychology, 94, 223-244.

Kuperman, V., Schreuder, R., Bertram, R., \& Baayen, R. H. (2009). Reading polymorphemic Dutch compounds: Toward a multiple route model of lexical processing. Journal of Experimental Psychology: Human Perception and Performance, 35, 876-895.

Lavric, A., Clapp, A., \& Rastle, K. (2007). ERP evidence of morphological analysis from orthography: A masked priming study. Journal of Cognitive Neuroscience, 19, 866-877. 
Libben, G., Gibson, M., Yoon, Y. B., \& Sandra, D. (2003). Compound fracture: The role of semantic transparency and morphological headedness. Brain and Language, 84, 50-64.

Marslen-Wilson, W. D., Bozie, M., \& Randall, B. (2008). Early decomposition in visual word recognition: Dissociating morphology, form, and meaning. Language and Cognitive Processes, 23, 394-421.

McCormick, S. F., Rastle, K., \& Davis, M. H. (2008). Is there a 'fete' in 'fetish'? Effects of orthographic opacity on morphoorthographic segmentation in visual word recognition. Journal of Memory and Language, 58, 307-326.

Morford, J. P., Wilkinson, E., Villwock, A., Pinar, P., \& Kroll, J. (2011). When deaf signers read English: Do written words activate their sign translations? Cognition, 118, 286-292.

Peng, D.-L., Li, Y.-P., \& Liu, Z.-Z. (1994). 重复启动下中文双字 词的识别 [Identification of Chinese two-character words under repetition priming conditions]. Acta Psychologica Sinica, 26, 393-400.

Peng, D.-L., Liu, Y., \& Wang, C.-M. (1999). How is access representation organized? The relation of polymorphemic words and their morphemes in Chinese. In J. Wang, A. W. Inhoff, \& H.-C. Chen
(Eds.), Reading Chinese script: A cognitive analysis (pp. 65-89). Mahwah, NJ: Erlbaum.

Pollatsek, A., \& Well, A. J. (1995). On the use of counterbalanced designs in cognitive research: A suggestion for a better and more powerful analysis. Journal of Experimental Psychology: Learning, Memory, and Cognition, 21, 785-794.

Rastle, K., \& Davis, M. H. (2008). Morphological decomposition based on the analysis of orthography. Language and Cognitive Processes, 23, 942-971.

Rastle, K., Davis, M. H., \& New, B. (2004). The broth in my brother's brothel: Morpho-orthographic segmentation in visual word recognition. Psychonomic Bulletin \& Review, 11, 1091-1098.

Thierry, G., \& Wu, Y. J. (2004). Electrophysiological evidence for language interference in late bilinguals. NeuroReport, 15, $1555-1558$.

Thierry, G., \& Wu, Y. J. (2007). Brain potentials reveal unconscious translation during foreign-language comprehension. Proceedings of the National Academy of Sciences, USA, 104, 12530-12535.

Wang, C., \& Peng, D. (2000). 重复启动作业中词的语义透明度的作 用 [The role of semantic transparencies in the processing of compound words]. Acta Psychologica Sinica, 32, 127-132. 